\title{
Fragmentos de identidade(s) em Cidade de Vidro, de Paul Auster
}

\section{Marcus Vinicius Matias}

Mestre pelo Programa de Pós-Graduaçāo em Letras

e Lingüistica, da Universidade Federal de Alagoas,

em Lingua Inglesa e suas Literaturas, com a

dissertaçāo Exploring the glassy maze: Paul Auster's

postmodern anti-detective fiction, sob a orientaçāo

da Prof ${ }^{3} r^{\mathrm{a}}$. Ildney Cavalcanti.

\section{ILDNey CavalcantI}

Professora e pesquisadora do PPGLL/FALE/UFAL.

Resumo: A partir da leitura de Cidade de Vidro, uma das histórias de The New York trilogy, de Paul Auster, analisamos a relaçāo entre a cidade e a desconstrução da identidade. Em um espaço urbano fragmentado, a linguagem, que veicula as negociaçōes, aflora por meio de uma série de significantes e significados instáveis.

Palavras-chave: Identidade; significante/ significado; linguagem; espaço urbano
Abstract: Through the analysis of City of Glass (1987), one of Paul Auster's short stories from The New York trilogy, the relationship between the city and the deconstruction of identity is observed. In a fragmented urban space, language, which functions as a vehicule for negociations, surfaces by means of a series of unstable signifiers and signifieds.

Key-words: Identity; signifier/signified; language; urban space 



\section{Desconstruindo a imagem através do espelho}

É provável que existam tantos modos diferentes de se conceber o que é uma cidade quantas são as cidades existentes. O mais simples diz que uma cidade é um assentamento humano no qual estranhos irão provavelmente se encontrar. [...]Nesse ambiente de estranhos cujas vidas se tocam, há um problema de platéia que guarda um parentesco com o problema de platéia que um ator enfrenta no palco. (SENNET, 1988, p. 58)

Cidade de Vidro (1985)' narra uma história metafísica de detetive ${ }^{2}$ que dialoga com as convenções do gênero. Segundo Porter (1981, p. 5), uma história de detetive pode ser definida como um texto "cuja principal ação se volta à tentativa de um investigador especialista em resolver um crime e levar o criminoso à justiça". No entanto, em vez de se chegar à solução de um caso/crime (como nas histórias clássicas), em Auster o protagonista se vê em um labirinto interpretativo de sua própria realidade, pondo em dúvida questões sobre quem ele realmente é. Ao tentar acompanhar a rotina de um ex-presidiário para evitar um suposto assassinato, o detetive, na história de Auster, acaba por se envolver em uma imbricada relação entre a busca de sua própria identidade e a multiplicidade de sentidos contraditórios que permeiam o espaço urbano.

Em Cidade de Vidro, a conexão entre a cidade e seus significantes e significados mostra-se muito mais complexa e inatingível, assumindo constantemente novas representações, na mesma proporção em que as identidades do protagonista Daniel Quinn - no papel de um suposto detetive - e de seu alter ego, Max Work, confundem-se numa relação que vai gradualmente se distorcendo ao longo da narrativa. Auster retrata, assim, as relações no espaço social enfatizadas pela produção desse espaço (o papel que o lar, o escritório, as ruas, etc., representam na organização social da cidade) e sua influência no processo de formação da identidade.

Segundo Marc Augé (2005, p. 73), "[...] um lugar
'A edição consultada para o presente estudo foi a de 1987, listada nas referências ao final. As citações foram retiradas dessa edição e serão seguidas pelas iniciais $\mathrm{CV}$ e números das páginas.

${ }^{2}$ De acordo com Patrícia Merivale e Susan Sweeney (1999) uma história metafísica de detetive "é um texto que parodia ou subverte as convenções tradicionais das histórias de detetive [...], com a intenção, ou pelo menos o efeito, de questionar os mistérios do ser e do conhecimento que transcendem a mera mecanização das narrativas de suspense" (p. 2). Salvo indicação, as traduções são nossas. 
${ }^{3}$ Augé se refere a um poema de Baudelaire, citado por Starobinski, para evocar os lugares e os ritmos antigos que parecem ecoar "indicadores do tempo que passa e que sobrevive. Perduram como as palavras que os expressam e ainda os expressarão". (AUGÉ, 2005, p. 73. pode ser definido como identitário, relacional e histórico", o que, a nosso ver, parece implicar uma relação estreita com a formação do self. Nesse sentido, poderíamos supor que se a um lugar não forem atribuídos os tipos de relações assinaladas, esse lugar poderá se transformar no que Augé denomina de "não-lugar". Para Augé:

A hipótese [...] defendida é a de que a supermodernidade é produtora de não lugares, isto é, de espaços que não são em si lugares antropológicos e que, contrariamente à modernidade baudelairiana ${ }^{3}$, não integram os lugares antigos: estes, repertoriados, classificados e promovidos a "lugares de memória", ocupam aí um lugar circunscrito e específico. (AUGÉ, 2005, p.73)

Na perspectiva de Augé, um não-lugar é um lugar transitório que se caracteriza por um movimento contínuo. Em tal deslocamento, as informações são normalmente absorvidas parcial e superficialmente, gerando uma percepção fictícia entre o olhar e a paisagem. "O espaço do[a] viajante", por exemplo, "seria o arquétipo do não-lugar" (ibidem, p. 81), uma vez que, para ele/a, a maior parte dos nomes dados aos lugares visitados enraízam-se na cultura do outro, e, sendo assim, não possuem qualquer relação identitária com o/a viajante. Desse modo, um espaço conceituado como lugar transforma-se em um não-lugar.

É por esse viés que, ficcionalmente, Auster questiona a relação transitória entre sujeito e espaço urbano. Tal característica de sua ficção pode ser aproximada às análises de Stuart Hall (2002) sobre identidade e cultura na pós-modernidade, segundo as quais, o sujeito não é constituído apenas por uma identidade única, com a qual, na concepção do sujeito iluminista, ele nasceria já formado e a manteria imutável em sua essência durante sua vida.

Aprofundando essa reflexão percebemos que o conceito de identidade também não pode ser limitado à constituição de uma "reciprocidade estável" entre seu "interior" e "exterior", como propõe a noção do sujeito sociológico, uma vez que as relações entre o "interior" e o "exterior" 
nem sempre são estáveis - pois constantemente ocorrem conflitos entre ambos. Portanto, segundo a teoria sobre o sujeito pós-moderno, desenvolvida por Hall, sugerimos que não existe uma identidade única, mas uma variedade de identidades que se conectam de acordo com o meio.

\section{Entrando no labirinto}

Daniel Quinn, um escritor que adotou o pseudônimo de William Wilson (pseudônimo utilizado por Quinn e alusão de Auster ao conto de Edgar Allan Poe) ${ }^{4}$, escreve histórias de detetive. Uma noite recebe, por engano, um telefonema de uma mulher à procura de um detetive particular chamado Paul Auster ${ }^{5}$. Após refletir sobre essa coincidência (visto que ele próprio escrevia histórias de detetive), Quinn resolve assumir a identidade desse detetive e aceita o caso, confiante na maneira como ele costuma lidar com as situações nas histórias que escreve. Ele aposta na previsibilidade dos acontecimentos.

A voz ao telefone é de Virginia Stillman, que quer contratar o detetive Auster para proteger seu marido, Peter Stillman Jr. Ela acha que o pai de Stillman Jr. pretende matálo, e conta que, há alguns anos atrás, Stillman pai trancou o filho em um quarto escuro por nove anos, como parte de uma experiência visando recuperar a língua original, a língua de Deus. Sua experiência foi descoberta casualmente, por conta de um incêndio em seu apartamento, o que resultou em sua prisão por treze anos. Agora que Stillman pai foi solto, Virginia teme pela vida do marido.

Contudo, ao contrário do que Quinn esperava (ao se dedicar completamente ao caso como se fosse um verdadeiro detetive, suas atitudes, envolvendo ordem e controle, são bem claras), as coisas passam a fugir de seu controle e se fragmentam em pedaços cada vez mais desconexos, uma vez que, desde o início, as formas e representações assumem múltiplas interpretações na reflexão de Quinn sobre o caso Stillman. Como afirma Jacques Derrida (apud HAI.L, 2002, p. 41), "existem sempre significados suplementares sobre os quais não temos qualquer controle,
4 A questão da intertextualidade nesta narrativa é estudada em Matias 2007.

${ }^{5}$ Usamos itálico para salientar o jogo metalingüistico construído através da ficcionalização do próprio autor, que aparece como personagem. 
${ }^{6}$ Quinn looked out the window and wondered if these were the same trees that Peter Stillman saw when he walked out into the air and the light. He wondered if Peter saw the same things he did, or whether the world was a different place for him. And if a tree was not a tree, he wondered what it really was. que surgirão e subverterão nossas tentativas para criar mundos fixos e estáveis".

Quinn olhava através da janela e pensava se aquelas eram as mesmas árvores que Peter Stillman vira quando caminhava em meio ao ar livre e à luz do dia. Ele pensava se Peter vira as mesmas coisas que ele, ou se o mundo era um lugar diferente para ele. E se uma árvore não era uma árvore, ele pensava o que ela realmente seria. ( $\mathrm{CV}, \mathrm{p} .59)^{6}$

Além da incerteza de como assumiria o caso Stillman, Quinn passa também a lidar com a ambivalência de viver e assumir a personalidade de uma outra pessoa, a do detetive Auster.

\section{O jogo entre identidade e lugar}

Na trama de Auster, os conflitos envolvendo identidade e linguagem vão gerando, em Quinn, dúvidas insolúveis, que, se assomando à sua investigação, continuam sem respostas até o final do livro, levando a uma situação sem saída ou esperança. Essa condição, entretanto, já lhe era de algum modo familiar, antes mesmo de resolver assumir a identidade do detetive Auster:

Logo após a morte de sua esposa e de seu filho, Quinn, aos poucos, vai se desfazendo dos amigos da mesma forma como se desfez do seu lugar no mundo, isolando-se em seu apartamento e mantendo contato com seu agente ou editor apenas por correspondência em caixa postal. Como o próprio narrador/autor ficcionalizado escreve em Cidade de Vidro, era "como se ele estivesse de alguma forma vivendo uma vida póstuma" (p.11) ou como se tivesse aos poucos apagando seu rastro da superfície dessa realidade/identidade que, cada vez mais, fazia menos sentido para ele.

Como afirma Ricardo Azevedo (2006, p. 12): “[Nas vastas cidades] o representar é requisito do cotidiano e, como toda representação implica códigos, sinais evidenciam e denunciam as condições sociais que as persona- 
gens aspiram ostentar". Ao contrário do que acontece em pequenas cidades de interior, nas grandes cidades há uma aglomeração de procedência heterogênea e um conjunto de atividades variadas, levando seus habitantes a adotarem modos singulares de inter-relacionamento em ambientes estranhos ou familiares: nas grandes cidades seus habitantes não se reconhecem.

Quinn gostava de vagar pelas ruas da cidade, como se andasse pelo labirinto de seus próprios pensamentos. Ele o fazia todos os dias sem nenhuma direção definida, mas "naquela que suas pernas o levavam" ( $\mathrm{CV}, \mathrm{p} .8)$, o que sempre lhe provocava a sensação de estar perdido não só na cidade, mas, também, perdido dentro de si mesmo.

Cada vez que ia caminhar, ele sentia como se estivesse se deixando para trás, e ao se entregar ao movimento das ruas, ao se reduzir a um olho-observador, ele era capaz de escapar da obrigação de pensar, e isso, mais do que qualquer coisa, era a medida exata da paz, um salutar vazio interior. (p. 8$)^{7}$

Como que se metamorfoseando nas ruas da cidade, por meio de um "olho observador" (a seeing eye), que reduz o self a uma espécie de "função de câmera", Quinn parece fazer parte das ruas, deslizando por elas como um grande pano de fundo. Nessa situação, passa a refletir sobre a fragilidade de se sustentar em uma identidade individual, em um eu único, e, pela via do anonimato, se fragmenta em meio à multidão, a ponto de se deixar absorver pelo turbilhão de formas e sentidos que o rodeavam a cada vez que saía para caminhar, à deriva, pelas ruas. De fato, o que parece levá-lo à sensação de paz é a possibilidade de assumir, nesse anonimato, o esquecimento de si como "inteiro". A necessidade sentida por Quinn de transitar por entre os não-lugares nos remete mais uma vez a Augé:

O movimento acrescenta à coexistência dos mundos e à experiência combinada do lugar antropológico e daquele que não o é mais [...] a experiência particular de uma forma de solidão e, em sentido
${ }^{7}$ Each time he took a walk, he felt as though he were leaving himself behind, and by giving himself up to the movement of the streets, by reducing himself to a seeing eye, he was able to escape the obligation to think, and this, more than anything else, brought him a measure of peace, a salutary emptiness within. 
${ }^{3}$ The detective is one who looks, who listens, who moves through this morass of objects and events in search of the thought, the idea that will pull all these things together and make sense of them.

${ }^{9} \mathrm{O}$ caderno vermelho assume, na narrative de Auster, um papel crucial em seu jogo metalingüístico. $\mathrm{O}$ enredo de Cidade de Vidro se desdobra a partir do conteúdo deste caderno. literal, de uma "tomada de posição" - a experiência daquele que, diante da paisagem que é obrigado a contemplar e que não pode contemplar, "toma pose" e tira da consciência dessa atitude um prazer raro e, às vezes, melancólico. (2005, p.81)

É então através da criação de histórias de detetive que Quinn encontra uma forma de dar sentido a essa mesma multiplicidade de significados. O que o atraía, ao escrever seus livros, era uma dinâmica previsível e, ainda assim, plena dos enredos: "tudo passa a ser essência; o centro do livro se desloca para cada evento que o impulsiona para frente. $\mathrm{O}$ centro, então, está em toda parte, e nenhuma circunferência pode ser traçada até o livro chegar ao fim" (CV, p. 15).

Nessa dinâmica, o papel do detetive consiste em decodificar os fatos através de uma leitura do espaço urbano, interpretando-os e ordenando-os a fim de manter a organização social. O mundo é, assim, um grande texto que se revela aos olhos do hábil leitor, o detetive: "O detetive é aquele que olha, que ouve, que se move através desse pântano de coisas e eventos em busca do pensamento, da idéia que irá pôr todas essas coisas juntas e dar-lhes sentido" (ibidem, loc.cit.) ${ }^{8}$.

Nesse contexto, ao assumir o papel de detetive, Quinn começa a seguir o suposto homicida Stillman pai e a anotar, em um caderno vermelho ${ }^{9}$, seu itinerário e os objetos que ele recolhe do chão, na tentativa de encontrar alguma relação com a possível ameaça de assassinato. Confuso, por não encontrar nenhuma conexão entre as caminhadas de Stillman pai e a vida de Stillman Jr., Quinn passa a analisar o itinerário dessas caminhadas com o auxílio de um mapa urbano. É quando ele percebe que o roteiro desenhado nesse mapa forma uma letra, e cada caminhada parece formar uma letra diferente, cuja combinação resulta na frase: ORRE DE BABEL (fragmento de: A TORRE DE BABEL). Não por acaso, esse foi o título de um dos livros de Stillman pai, escrito antes de ir para cadeia, no qual ele relata a "queda" da linguagem, que levou à separação entre o homem e Deus, "os nomes se destacaram das coisas" (CV, p. 70). 
A descoberta de Quinn nos remete ao pensamento de De Certeau (1988) sobre a lógica espacial, que busca elaborar um mapa/texto no trajeto dos passantes. Para De Certeau, andar "é um ato espacial do lugar (do mesmo modo que o ato de fala é um ato acústico da língua)". Segundo esse autor, o caminhar pode ser entendido como "um espaço de enunciação" (1988, p. 98), o que evoca, em nossa leitura, a função do detetive que lê o espaço urbano como um texto. No entanto, para De Certeau, se os transeuntes "escrevem" na cidade, eles fazem isso "sem poder ler o que foi escrito", embora todos juntos "componham uma coletânea de histórias onde não há autor nem espectador, formada por fragmentos de trajetórias e espaços alterados" (ibidem, p.93). De Certeau pretende "construir a ficção de que criar leitores torna legível a complexidade da cidade e imobiliza sua opaca mobilidade em um texto transparente". Esse leitor observador estaria posicionado em um ponto privilegiado a partir do qual ele poderia ver o texto como um todo. No papel de detetive, Quinn busca esse ponto de vista sobre o todo, esse conhecimento do todo, ao seguir Stillman pai e mapear seu itinerário. Esse desejo intensifica-se pela nova função de investigador que ele assume, a qual se baseia em resolver os mistérios do mundo através da construção de um texto coerente. No entanto, o suposto conhecimento sobre o texto urbano seria apenas "a ficção do conhecimento" (ibidem, p. 92).

A segurança que Quinn deposita na habilidade do detetive em decodificar o mundo não só reflete sua crença em uma sucinta economia lingüística onde "não há desperdício de frases ou palavras" e "nenhuma palavra que não seja significativa" (CV, p. 15), como também em manter uma identidade estável, única e previsível, assim como a organização racional do espaço social. É desse modo que a possibilidade de criar esquemas ficcionais através de histórias de detetive garante a Quinn um sentido ao seu self e uma posição no mundo, porque somente através dos olhos do detetive é que esse mundo passa a ter sentido.

Assim, as noções de texto e identidade que 
permeiam as histórias tradicionais de detetive estão para Quinn também interligadas à sua concepção de espaço, uma vez que é no contexto urbano que o detetive "lê" as suas pistas. Nas histórias clássicas, por exemplo, os espaços são protagonistas do mistério, pois eles geralmente abrigam os crimes. A biblioteca de uma casa, um trem, um hotel isolado, etc., são lugares onde o detetive busca e encontra pistas e ligações que o conduzirão aos prováveis suspeitos. Lefebvre (1991) vai ainda além disso, quando afirma que os sujeitos não são constituídos apenas pela linguagem, mas também pelos espaços: "todos os 'sujeitos' estão situados em um espaço no qual eles devem reconhecer a si próprios ou se perder de si" (ibidem, p. 35), e explica que essa negociação envolve aceitar "um papel e uma função, implicando em uma localização, um lugar na sociedade, uma posição" (ibidem, p.182 -183).

A noção de lar, por exemplo, nos remete à idéia de que ao possuir uma moradia, um ponto fixo no espaço urbano, passamos a constituir uma identidade neste cenário: um lugar no mundo. Como Doreen Massey argumenta, "um lugar chamado lar é um ancoradouro que oferece estabilidade espacial, uma estrutura geométrica ou arquitetônica imutável a que sempre podemos retornar, assim como a uma fonte de identidade sem conflitos" (1994, p.151).

Com base nessa pressuposição, seria possível concluir que é na estabilidade do lar que se fundamentam uma sociedade e identidade estáveis. Contudo, em Cidade de Vidro, essa estabilidade é questionada não somente pelo conflito de identidades, mas desde o momento em que Quinn atende ao telefonema em seu apartamento que, na verdade, não é seu, é alugado, ou seja, em vez de um símbolo de permanência, tem-se um lugar temporário. Além disso, é justamente fora de casa que Quinn passa a maior parte de seu tempo, tanto quando vaga sem destino pelas ruas, quanto ao seguir Stillman pai. A certeza de que sempre haverá uma casa para onde ele possa retornar está associada apenas à crença de que haveria um eu único, uma identidade imutável e fixa, semelhante ao ponto fixo do lar no espaço urbano. Isso significa que a perda de um 
levará à perda do outro e que manter essa estabilidade é um ato tão desesperador quanto a busca de si ao se perder pelas ruas.

Quinn, portanto, considerava sua casa como um lugar estável e seguro, que lhe garantia a segurança de suas histórias ficcionais. Essas eram construídas diante dele como uma ponte para um mundo onde tudo era mantido em seu lugar pelas ações do detetive. Contudo, essas histórias aos poucos vão se transformando em um perigoso jogo de espelhos, no qual Quinn passa a se ver como Wilson, que por sua vez assume a voz de seu narrador fictício, Max Work.

Na tríade de egos que Quinn se transformou, Wilson servia como uma espécie de ventríloquo, o próprio Quinn era o boneco, e Work era a voz que dava propósito a tudo. Se Wilson era uma ilusão, ele, contudo, justificava a vida dos outros dois. (CV, p.11-12) $)^{10}$

Como Quinn já estava há muito tempo confinado em um apartamento, vivendo como um espectro e longe de uma existência social, ele gradualmente se desfaz de sua percepção sobre si mesmo como uma pessoa real. De fato, seu único contato com o mundo passou a ser através de William Wilson, e é desse modo que seu "protagonista metaficcional", Max Work, "assume" a concepção de Quinn sobre a vida, representando seu alter ego: como que diante de um espelho, Quinn se coloca diante da imagem de Work. Suas atitudes passam a ser inversamente proporcionais: se Quinn sentia pena de si mesmo, Max Work, por outro lado, representava uma pessoa decidida e arrogante, características típicas do detetive dos clássicos hard-boiled. Para Quinn, "seu detetive tinha necessariamente que ser real. A natureza dos livros exigia isso" (CV, p. 10). Nesse contexto, quanto mais Max Work assumia sua existência no mundo do outro (o mundo "real" dos leitores ficcionais), mais Quinn se retirava desse mundo, o que é evidenciado na citação acima pela imagem de um boneco (dummy), um ser sem voz, que desempenhava o ato de escrever guiado por Max Work. Este último manti-
${ }^{10}$ In the triad of selves that Quinn had become, Wilson served as a kind of ventriloquist, Quinn himself was the dummy, and Work was the animated voice that gave purpose to the enterprise. If Wilson was an illusion, he nevertheless justified the lives of the other two. 
${ }^{11}$ Lembremos que, no conto de Poe, William Wilson atravessa uma crise identitária. nha a salvo o mundo ficcional de Quinn, como se fosse seu esconderijo. Através dessa estrutura metaficcional, que recorre ao jogo intertextual através de William Wilson ${ }^{11}$, Auster apresenta ao/à leitor/a, uma problemática crise de identidade sofrida por Quinn, que será desenvolvida na dinâmica da narrativa.

Em Cidade de Vidro, os conflitos envolvendo as questões de identidade, sobretudo quando se trata da possibilidade de assumirmos mais de uma, são intensificados quando o papel de um suposto detetive no caso Stillman é assomado à tríade de egos já vivida por Quinn, levando-o a uma crise de identidade ainda mais complexa. Ao ser tratado pelos Stillman como um detetive de verdade, Quinn incorpora a visão de mundo desse novo personagem. Esse complexo jogo identitário de Cidade de Vidro mais uma vez fornece os elementos para a ligação com as teorizações de Hall, segundo o qual "a identidade surge não tanto da plenitude da identidade que já está dentro de nós como indivíduos, mas $[. .$.$] pelas formas através das quais nós ima-$ ginamos ser vistos por outros" (HALL, 2002, p. 39).

Desse modo, as referências que Quinn tira das histórias de detetive orientam, de certa forma, suas noções sobre o mundo, dando sentido para seu eu. Assim, ao assumir um caso "real" (e sob a influência dele), Quinn percebe que o padrão do seu mundo ficcional (no qual ele estava vivendo) começa a se desconstruir. Junto com os padrões pré-estabelecidos, ou seja, as formas fixas como essas histórias se organizavam, é desconstruída também sua noção sobre si mesmo no mundo. A fragmentação cada vez maior do seu eu único e "inteiro" fragmentou também a certeza de "que poderia a qualquer momento voltar a ser Quinn" (CV, p. 82), ou seja, aquele mesmo Quinn de outrora, como que purificado das experiências e influências sofridas durante a investigação do caso Stillman.

Ele se assemelha, aqui, ao sujeito da modernidade tardia que Hall nos apresenta como aquele cuja identidade é formada a partir de relações dinâmicas, as quais nem sempre coexistem pacificamente. Quinn transforma-se exatamente nesse sujeito da modernidade tardia. 
[A் medida em que os sistemas de significação e representação cultural se multiplicam, somos confrontados por uma multiplicidade desconcertante e cambiante de identidades possíveis, com cada uma das quais poderíamos nos identificar. (HALL, 2002, p. 13)

Há, portanto, uma analogia entre o deslocamento de identidades proposto por Hall e a forma como Quinn engendra os enredos de seus livros: neles o centro se desloca para diferentes eventos, causando deslocamentos identitários. A questão é que, como vimos, "na vida real" de Quinn, ao contrário de suas histórias, nas quais os casos sempre chegam a uma solução final, tais deslocamentos fogem de seu controle. Isso leva ao colapso de sua própria noção de identidade como um lugar seguro, porque o centro da história, seu núcleo catalisador, fragmenta-se à medida que os acontecimentos passam a assumir vários sentidos e inúmeras interpretações. Isso contradiz sua crença segundo a qual o detetive, ao possuir a habilidade em decodificar o mundo (em uma estreita economia lingüística), está, ao mesmo tempo, garantindo uma identidade estável, ao organizar as relações espaciais na sociedade.

No caso de Quinn, sua situação acentua-se no momento em que ele perde a trilha de Stillman pai e também a de Stillman Jr. e Virginia. Isso porque, ao perder o contato com eles, e, conseqüentemente, o motivo de continuar no caso, o motivo de sua participação naquele mundo torna-se inócuo.

Em um momento da narração, Quinn decide instalar-se em um beco em frente à casa dos Stillman, no outro lado da rua, permanecendo de vigília na tentativa de recuperar o contato com eles. Aos poucos, Quinn vai se adaptando ao desconforto e às inconveniências de sua posição no beco, até se transformar radicalmente em um mendigo. É nesse momento que começa a perceber detalhes da cidade que até então ignorava: a presença de vagabundos, de bêbados e das senhoras com suas sacolas de compras, ou seja, os "ninguém" que habitam as ruas como seres invisíveis, e os quais, até então, o detetive não conseguira colocar em lugar nenhum e nem encontrar uma so- 
lução para eles.

Anthony Vidler (1992) refere-se ao mendigo como uma ameaça ao bem estar dos burgueses que constroem seus apartamentos acima do contágio das ruas da cidade, em busca de uma assepsia urbana, como exemplo de uma clara demarcação de classes na produção dos espaços urbanos. Em sua análise, Vidler considera que

o espaço supostamente esconde, em seus recessos escuros e margens esquecidas, todos os objetos de temor e fobia que têm retornado com tanta insistência para assombrar a imaginação daqueles que tentam criar guaritas de vigilância para proteger sua saúde e felicidade. (VIDLER, 1992, p. 167)

Seguindo a trajetória de Quinn, que morava em um desses espaços isolados, vindo a se transformar, gradualmente, em um mendigo, levantamos duas hipóteses. A primeira é que o contágio com os mendigos da cidade corroeu, literalmente falando, seu corpo burguês e seu bem estar social. A segunda é que as fronteiras que separam e protegem as casas ou escritórios, fronteiras, de resto, resultantes de uma demarcação social da cultura, podem ser desconstruídas da mesma forma como foram postas. Logo, Auster parece levantar aqui um questionamento sobre a desconstrução da identidade, metaforizada pela produção do espaço, mais especificamente em se tratando da representação do lar e das ruas.

Quando Quinn finalmente deixa o beco, ele se vê em um reflexo da vitrine de uma loja, mas não se reconhece, "ele tenta se lembrar de como era antes, mas é muito difícil para ele" (CV, p. 183). Na esperança de que tudo voltasse a ser como antes, e numa busca de recuperação de sua identidade inicial, Quinn retorna ao apartamento. Contudo, da mesma forma que seu verdadeiro nome e sua antiga imagem escapuliram por entre seus dedos, o apartamento (que representava uma referência segura no espaço urbano, ajudando-o a construir sua noção de identidade) não mais existia. Ele descobre que outra pessoa o havia alugado e que seus objetos pessoais 
haviam sido vendidos como pagamento do aluguel atrasado.

fato é que, ao assumir a identidade de uma outra pessoa (o detetive), Quinn associa o infortúnio pelo qual havia passado, julgando que sua identidade verdadeira continuaria íntegra e imutável. Quando se dá conta desse terrível engano, ele percebe que "[havia chegado] ao fim de si mesmo. Podia sentir isso agora, como se uma grande verdade tivesse finalmente se revelado para ele. Já não restava mais nada" (CV, p. 191). Apesar da fragmentação da identidade, que ele experimenta no início da história, e da transformação sofrida pela sua aparência, é só ao perder seu apartamento - seu espaço material no mundo - que Quinn desiste de toda sua esperança de voltar a ser o que era antes.

Uma vez que Quinn já não possui uma representação material no espaço urbano, nem sua identidade no espaço social, ele, como mendigo, assume agora a posição de um anti-detetive, ou seja, aquele que, em vez de manter a ordem social, rompe suas fronteiras, habitando fora desse sistema que é a sociedade, quebrando, portanto, todas as barreiras de contenção mantidas pelo detetive. É dessa forma, vagando à deriva entre as fronteiras, que Quinn chega ao apartamento dos Stillman, encontrando a porta aberta, mas ninguém lá.

Quinn resolve então habitar um dos cômodos do apartamento, onde ele se desfaz do que lhe pertencia (roupas, sapatos e relógio). Não se desfaz do caderno vermelho, porém. Deitado, nu, no chão do quarto, olha o teto e reflete sobre seu destino. Tenta ordenar os acontecimentos em seu caderno, mas aos poucos perde o interesse por eles e divaga. Sua última frase é "[...] o que irá acontecer quando as páginas acabarem?" (CV, p. 200). Quinn vai aos poucos mergulhando em sua própria ausência. Tal como palavras desconexas em páginas soltas, ele assume uma representação simbólica de suas incertezas. Fica claro aqui também que a identidade/história do personagem criado por Auster está ligada à textualização, sendo construída enquanto narrativa, mais uma vez sinalizando o acentuado jogo metalingüístico desse texto.

Nesse ponto da história, é inevitável que se crie uma suspeita em relação ao papel desempenhado pelos 
Stillman até então, sobretudo pelo próprio Stillman Jr. Isso leva a várias vertentes de interpretação. Para a presente leitura, interessa-nos a que se baseia na contradição situada no estado de abandono/ausência sofrido por Quinn ao fim da narrativa, o que é a representação inversa dos Stillman. Em uma tradução literal, o nome Stillman pode significar, em português, o equivalente a ainda homem, ou seja, ainda existente. Isso, por sua vez, sugere que os Stillman não desapareceram, mas ainda continuam a espreitar os movimentos de Quinn, como que se houvesse, de fato, uma armadilha criada desde o início para ele.

Uma vez que essa é uma história de detetive, ou melhor, uma história que questiona o poder do detetive, esta possibilidade de interpretação parece estar mais de acordo com a proposta narrativa de Auster, ao mesmo tempo que estabelece uma conexão com os livros seguintes da trilogia: em Ghost (1986), o segundo livro da série, o detetive também é vítima da trama criada pelo vilão.

Em relação ao eu pós-moderno, ou o eu da "modernidade tardia", como prefere Hall, podemos concluir aqui que nessa obra de Auster, Cidade de Vidro, é possivel perceber como o personagem assume diferentes papéis nas negociações interpessoais e como seus valores e crenças se transformam em contato com o Outro. Negociando significados com o Outro, Quinn termina se reencontrando, parecendo estar suspenso no que Geertz (1973) chama de "teia de significados". Suspensos nessa mesma teia estamos nós, leitores/as de Cidade de Vidro. 


\section{Referências}

AUGÉ, Marc. Não-lugares: Introdução a uma antropologia da supermodernidade. Tradução Maria Lúcia Pereira. Campinas, SP: Papirus, 1994.

AUSTER, Paul. City of Glass - Vol. 1 of the New York trilogy. New York: Penguin Books, 1987.

AZEVEDO, Ricardo Marques. Metrópole: Abstração. São Paulo: Perspectiva, 2006.

DE CERTEAU, Michel. The practice of everyday life. Translated by Steven Rendall. Berkely: University of California, 1988.

GEERTZ, C. The interpretation of cultures. New York: Basic Books, 1973.

HALL, Stuart. A identidade cultural na pós-modernidade. Tradução Tomaz Tadeu da Silva e Guacira Lopes Louro. Rio de Janeiro: DP\&A Editora, 2002.

LEFEBVRE, Henri. The production of space. Translated by Donald Nicholsan-Smith. Oxford and Cambridge, Mass.: Blackwell, 1991.

MASSEY, Doreen. Space, place, and gender. Minneapolis: University of Minessota, 1994.

MATIAS, Marcus V. Exploring the glassy maze: Paul Auster's postmodern anti-detective fiction. 2007. 118 f. Dissertação (Mestrado em Língua Inglesa e suas Literaturas) - Faculdade de Letras, Universidade Federal de Alagoas, Maceió, 2007. MERIVALE, Patricia \& SWEENEY, Susan E.. Detecting texts: The metaphysical detective story from Poe to postmodernism. Philadelphia: University of Pennsylvania, 1999.

PORTER, Dennis. Antidetection. The Pursuit of Crime: Art and Ideology in Detective Fiction. New Haven: Yale UP, 1981. SENNET, Richard. O declínio do homem público: As tiranias da intimidade. Tradução Lygia Araújo Watanabe. São Paulo: Companhia das Letras, 1988.

VIDLER, Antony. The Architectural uncanny: essays in the modern unhomely. Cambridge Mass: MIT, 1992. 